Article

\title{
Fabrication of Iridium Oxide/Platinum Composite Film on Titanium Substrate for High-Performance Neurostimulation Electrodes
}

\author{
Tsai-Wei Chung ${ }^{1}$, Chih-Ning Huang ${ }^{1}$, Po-Chun Chen ${ }^{1, *}$, Toshihiko Noda ${ }^{2}$, Takashi Tokuda ${ }^{2}$ \\ and Jun Ohta ${ }^{2}$ D \\ 1 Department of Materials \& Mineral Resources Engineering, National Taipei University of Technology, \\ Taipei 106, Taiwan; uranusen@gmail.com (T.-W.C.); ek57592671@gmail.com (C.-N.H.) \\ 2 Graduate School of Materials Science, Nara Institute of Science and Technology, Ikoma, Nara 630-0192, \\ Japan; t-noda@ms.naist.jp (T.N.); tokuda@ms.naist.jp (T.T.); ohta@ms.naist.jp (J.O.) \\ * Correspondence: cpc@mail.ntut.edu.tw; Tel.: +886-2-2771-2171
}

Received: 16 October 2018; Accepted: 22 November 2018; Published: 23 November 2018

\begin{abstract}
Electrode materials for neural stimulation have been widely investigated for implantable devices. Among them, iridium and iridium oxide are attractive materials for bio-interface applications due to their desirable stability, electrochemical performance, and biocompatibility. In this study, iridium oxide/platinum $\left(\mathrm{IrO}_{x} / \mathrm{Pt}\right)$ composite films were successfully fabricated on titanium substrates by chemical bath deposition and these films are expected to be used as biocompatible stimulation electrodes. We modified the film compositions to optimize the performances. In addition, these $\mathrm{IrO}_{x} / \mathrm{Pt}$ composite films were characterized before and after annealing by SEM and XRD. We also identified the hydrophilicity of these iridium oxide/platinum composite films by measuring contact angles. Finally, the charge storage capacities of these iridium oxide/platinum composite films were evaluated by an electrochemical workstation. As a result, the charge storage capacities of the iridium oxide/platinum composite films are largely increased, and this leads to a very efficient neurostimulation electrode. Additionally, we successfully demonstrated the chemical bath deposition of $\mathrm{IrO}_{x}$ film on the surface of the bullet-shaped titanium microelectrode.
\end{abstract}

Keywords: $\mathrm{IrO}_{x} / \mathrm{Pt}$ composite film; stimulation electrodes; biocompatible thin film; bullet-shaped microelectrode

\section{Introduction}

The importance of biomedical engineering has raised considerable attention recently, especially on implantable neural-interacting prosthesis [1]. Titanium and its alloys have been confirmed as effective groups of traditional biomaterials [2]. Titanium has exceptional corrosion resistance in the physiological environment, therefore, is the chosen material for many structural implantable devices [3]. For instance, Noda et al. reported the development of an implantable neurostimulation system based on structural titanium microelectrodes [4]. A major limiting factor is the lack of stimulation electrodes with both reasonable performance, stability, and safety [5]. The development of stimulation electrodes requires the ability to inject electrical charges to produce a response without any tissue damage at the stimulation site. The electrode materials must be chosen and examined carefully.

Safe neural stimulation requires a reversible charge injection process which can be achieved either by a capacitive process or by a faradaic reversible reaction. The capacitive stimulation electrodes allow signal transmitting to neural tissues by a dielectric film [6]. However, only a limited amount of charge can be stored across the electrode interface. In general, electrostimulation with reversible faradaic reactions brings better charge injection performance than that with capacitive 
charge storage. Stimulation electrode materials operating in a faradaic mechanism include platinum, platinum/iridium alloy, iridium oxide, and poly(3,4-ethylenedioxythiophene) (PEDOT) [1,7,8]. Among them, iridium oxide can sufficiently provide necessary charge for stimulation without damaging surrounding tissues by electrochemical reduction and oxidation reactions at the electrode interface [9]. Additionally, advantages such as high charge injection capability, desirable stability, and requisite biocompatibility render iridium oxide to become the most promising material for implantable neurostimulation electrodes.

Iridium oxide has received substantial attention in recent years because of its unique ability to inject electric charge and its resistance to corrosion [10]. Iridium oxide is formed with ionic bonds and the hybridized s orbitals are fully occupied with electrons, which lead to notable thermal and chemical stability [11]. Several deposition techniques have been developed, including thermal decomposition, reactive sputtering, electrochemical activation, and electrodeposition [7,9,12-15]. However, some limitations for the processes listed above have been revealed. For instance, curved titanium substrates are not suitable for physical vapor deposition (PVD). Please define if appropriate. processes such as sputtering which causes cracking due to poor adhesion at the edge. Furthermore, titanium substrates are not suitable working electrodes for electrodeposition in most scenarios [4]. Therefore, an alternative solution for the iridium oxide synthesis is chemical bath deposition (CIROF) [16,17]. In chemical bath deposition, the precursor of Ir-ions undergoes oxidation reactions and forms film on the substrates initiated by selective oxidizers. This approach does not require an externally-imposed current/voltage and thus an insulator can be used as the substrate for film growth. Titanium substrates coated with iridium oxide by the wet synthesis process can overcome the difficulty of electrodeposition.

A neurostimulation electrode plays a critical role in determining the performance of the bioelectronics [18]. In this study, we developed iridium oxide/platinum composite films on titanium substrates by a multi-step chemical bath deposition and these films are expected to be used as biocompatible stimulation electrodes. We modified the film composition in order to optimize the performance of the iridium oxide/platinum composite films on titanium substrates for neurostimulation devices [19]. Additionally, we employed the chemical bath deposition of $\operatorname{IrO} x$ on the surface of a bullet-shape titanium microelectrode to validate the process we developed in this study on a practical device.

\section{Materials and Methods}

Based on previous results, a chemical bath deposition has been developed to fabricate high-quality iridium oxide films with thicknesses in the range from 50 to $1000 \mathrm{~nm}$ [16,17]. Therefore, a multi-step method can be used to meet the required film thickness. In this study, titanium sheets $\left(1 \times 3 \mathrm{~cm}^{2}\right)$ were cleaned and granulated for increasing adhesion of the following coatings by a dilute HF solution $(10 \%)$ for $1 \mathrm{~min}$ at room temperature [20]. Different compositions of $\mathrm{IrO}_{x} / \mathrm{Pt}$ composite films were prepared by the chemical bath deposition of iridium oxide on sputtered platinum film on the granulated titanium sheets. The plating bath of iridium oxide contained $0.01 \mathrm{M}$ of sodium hexachloroiridate (III) hydrate $\left(\mathrm{Na}_{3} \mathrm{IrCl}_{6} \cdot x \mathrm{H}_{2} \mathrm{O}\right.$, Sigma-Aldrich, St. Louis, $\left.\mathrm{MO}, \mathrm{USA}\right), 0.15 \mathrm{M}$ of sodium hypochlorite $(\mathrm{NaClO}$, SHOWA, Gyoda, Japan), $0.03 \mathrm{M}$ of sodium hydroxide ( $\mathrm{NaOH}$, Mallinchrodt Pharmaceuticals, Dublin, Ireland), and $0.01 \mathrm{M}$ of sodium nitrite $\left(\mathrm{NaNO}_{2}\right.$, SHOWA, Gyoda, Japan). Subsequently, the Ti and Pt-coated Ti sheets underwent a chemical bath deposition of iridium oxide at $25{ }^{\circ} \mathrm{C}$ for $4 \mathrm{~h}$. The ratios of the $\mathrm{IrO}_{x} / \mathrm{Pt}$ composite films are 0 to $100 \mathrm{~nm}, 100$ to $200 \mathrm{~nm}, 200$ to $100 \mathrm{~nm}$, and 300 to $0 \mathrm{~nm}$. After the $\mathrm{IrO}_{x} / \mathrm{Pt}$ composite films were formed, a heat treatment was conducted at $450{ }^{\circ} \mathrm{C}$ for $2 \mathrm{~h}$ in air. In addition, we performed the same chemical bath deposition of $\mathrm{IrO}_{x}$ on a bullet-shape titanium electrode which is $0.5 \mathrm{~mm}$ in diameter.

The surface morphologies of our samples were analyzed using a scanning electron microscope (FESEM; Hitachi SU-8010, Hitachi, Ltd., Tokyo, Japan) with a $15 \mathrm{keV}$ operating voltage. An X-ray diffractometer (XRD; Bruker D8 Discover, Bruker, Billerica, MA, USA) with a $1.54 \AA$ $\mathrm{Cu} \mathrm{K} \alpha$ target was employed to identify the characteristic peaks; the scan rate was $0.05^{\circ} / \mathrm{s}$ from $20^{\circ}$ to $80^{\circ}$. 
The charge storage capacity (CSC) was determined by integration of the cathodic current in a potential window for $\mathrm{IrO}_{x}$ and $\mathrm{Pt}$ between -0.6 to $0.8 \mathrm{~V}$. It has become common practice to characterize the stimulation electrodes by their CSC values. The CSC is calculated from the time integral of the cathodic current in a slow-sweep-rate cyclic voltammetry over a potential range that is just within the water electrolysis window $\left(-0.6-0.8 \mathrm{~V}\right.$ for $\mathrm{IrO}_{x}$ and $\left.\mathrm{Pt}\right)$. An electrochemical workstation (CHI 614E, CH Instruments, Inc., Austin, TX, USA) was employed to obtain those electrical properties. The geometric surface area was $0.386 \mathrm{~cm}^{2}$. Cyclic voltammetry was taken as a sweep rate of $50 \mathrm{mV} / \mathrm{s}$ from -0.6 to $0.8 \mathrm{~V}$. All the experiments were taken in phosphate buffer saline (PBS).

The biocompatibility of the $\mathrm{IrO}_{x} / \mathrm{Pt}$ composited films was evaluated by a sulforhodamine B (SRB) assay. MDA-MB-231 cells were seeded on different surfaces at a density of 1000 cells $/ \mathrm{cm}^{2}$. After 7 days, surfaces were washed twice with an excess of phosphate buffered saline (PBS) to remove any dead cells or debris. Cells were then fixed by immersing surfaces in $10 \%$ trichloroacetic acid (TCA) overnight at $4{ }^{\circ} \mathrm{C}$. The next day, cells were washed 5 times with double distilled water (DDW) and allowed to air dry. Cells were then stained for $1 \mathrm{~h}$ with $0.4 \%$ SRB (prepared in $1 \%$ acetic acid). Samples were washed 4 times with $1 \%$ acetic acid and air dried. Samples were then immersed in a $10 \mathrm{mM}$ Tris base for $30 \mathrm{~min}$. Optical density (OD) was recorded at $540 \mathrm{~nm}$ using an ELISA reader.

\section{Results and Discussion}

The adhesion of the first coated layer plays a key factor in the stability of the film synthesized by multi-step chemical bath deposition. Platinum, especially, has been reported that its adhesion issue causes peeling of the deposited film [21]. The granulated titanium can sufficiently increase the adhesion of sputtered platinum film on the titanium surface. Figure 1 shows the optical microscope images of titanium surface before and after surface granulating process. The treated titanium shown in Figure 1b, presents more and finer grains compared to the raw titanium sheet shown in Figure 1a. Therefore, the adhesion of the $\mathrm{IrO}_{x} / \mathrm{Pt}$ composite films on titanium substrate can be increased.

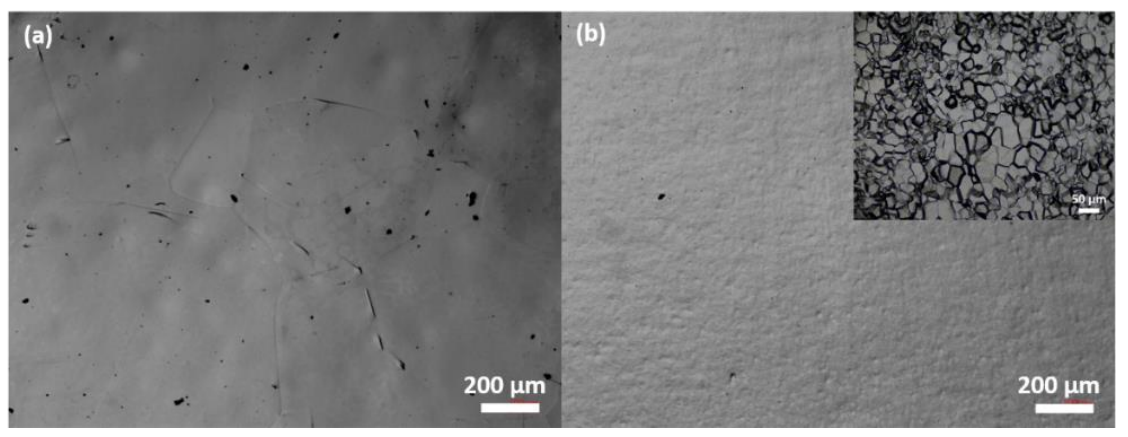

Figure 1. Optical microscope images of (a) untreated Ti foil; and (b) granulated Ti foil.

Figure 2 shows SEM images of the $\mathrm{IrO}_{x} / \mathrm{Pt}$ composite films. Figure $2 \mathrm{a}$ is the sputtered platinum on titanium substrate; some particles can be observed on its surface. Figure $2 \mathrm{~b}-\mathrm{d}$ show top-view SEM images of $100 / 200 \mathrm{~nm}, 200 / 100 \mathrm{~nm}$, and $300 / 0 \mathrm{~nm}$ of $\mathrm{IrO}_{x} / \mathrm{Pt}$ composite films, respectively. As shown in Figure $2 b-d$, the Ti substrates were fully covered by a dense layer of $\operatorname{IrO}_{x}$ and $\operatorname{IrO}_{x}$ particles on the surfaces. More particles appeared on the $200 / 100 \mathrm{~nm}$ of $\mathrm{IrO}_{x} / \mathrm{Pt}$ composite film, as shown in Figure 2c, than that on the $300 / 0 \mathrm{~nm}$ composite film, as shown in Figure $2 \mathrm{~d}$. Although thicker $\mathrm{IrO}_{x}$ films generally have more particles by chemical bath deposition, the sputtered platinum provides more nucleation sites compared to the pure titanium substrate. The contact angles also altered with the composition of the coated films as listed in Table 1. A negative correlation can be found between the thickness of $\operatorname{IrO}_{x}$ films and measured contact angles. It implies that composite films become more hydrophilic along with the increasing thickness of $\mathrm{IrO}_{x}$ film. The result matches the relationship between thickness and hydrophilicity reported by Miyashita et al. [22]. The thicker $\mathrm{IrO}_{x}$ film by chemical bath deposition presented more hydrophilicity, which is a desirable property for an implantable material. 


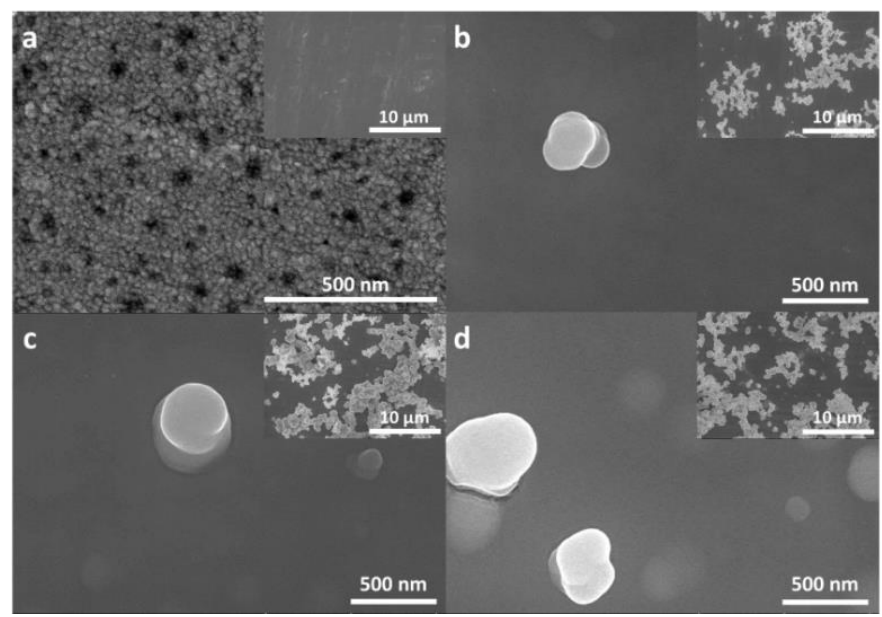

Figure 2. Top-view SEM images of annealed $\mathrm{IrO}_{x}$-Pt composite films on Ti substrate; (a) sputtered $\mathrm{Pt}$, (b) $100 \mathrm{~nm} / 200 \mathrm{~nm}$ of $\mathrm{IrO}_{x} / \mathrm{Pt}$, (c) $200 \mathrm{~nm} / 100 \mathrm{~nm}$ of $\mathrm{IrO}_{x} / \mathrm{Pt}$, and (d) $300 \mathrm{~nm} / 0 \mathrm{~nm}$ of $\mathrm{IrO}_{x}$.

Table 1. A summary of relations between $\mathrm{IrO}_{x} / \mathrm{Pt}$ ratio and contact angle.

\begin{tabular}{cc}
\hline IrO $_{x} /$ Pt Ratio & Contact Angle \\
\hline $0 / 100$ & 59.44 \\
$100 / 200$ & 24.48 \\
$200 / 100$ & 12.22 \\
$300 / 0$ & 5.58 \\
\hline
\end{tabular}

The crystallinity of the CIROF was improved by annealing the as-deposited film at $450{ }^{\circ} \mathrm{C}$ for $2 \mathrm{~h}$ in air. Figure 3 provides the XRD patterns of the annealed $\mathrm{IrO}_{x} / \mathrm{Pt}$ composite films. The as-deposited film was amorphous but after annealing, the crystalline rutile phase of $\mathrm{IrO}_{2}$ was confirmed by comparing with the standard $\mathrm{IrO}_{2}$ pattern (ICDD 00-043-1019), Pt pattern (ICDD 00-001-1194), and Ti Pattern (ICDD 01-089-5009). The crystalline film is expected to reduce defects and improve the film stability. We can determine the charge storage capacity (CSC) of the films by performing the cyclic voltammetry tests in PBS solution. It has become common practice to characterize the stimulation electrodes by their CSC, which is essentially a measurement of the total amount of charge available for a stimulation pulse.

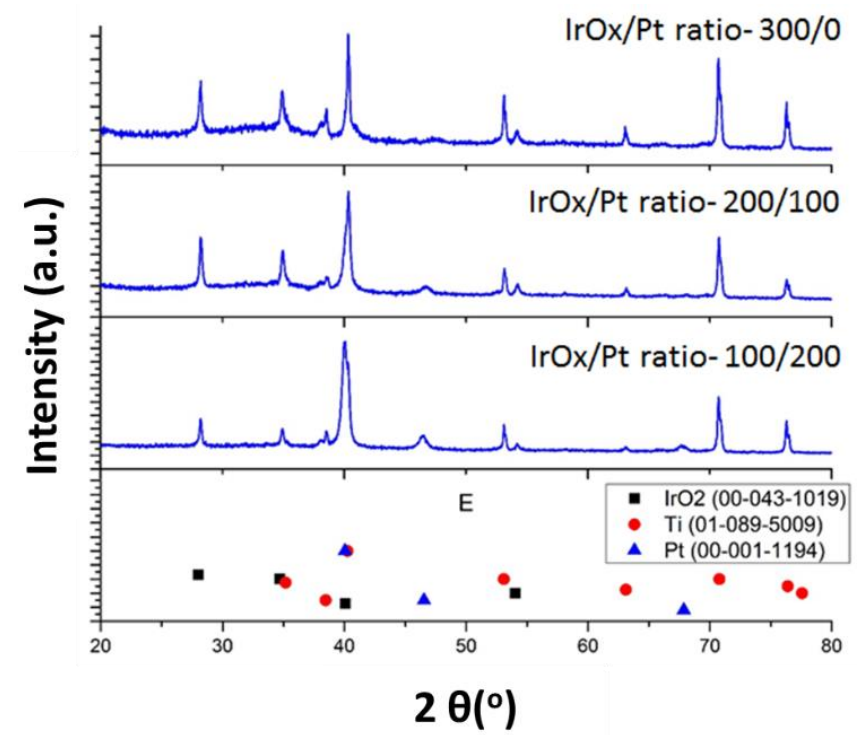

Figure 3. XRD patterns of different compositions of $\mathrm{IrO}_{x}-\mathrm{Pt}$ composite films on Ti substrates with $\mathrm{IrO}_{x} / \mathrm{Pt}$ ratio of (a) 300/0, (b) 200/100, (c) 100/200, and (d) ICDD standards of $\mathrm{IrO}_{2}$, Ti, and Pt. 
The cyclic voltammograms (CV) shown in Figure 4 are the as-deposited and annealed $\mathrm{IrO}_{x} / \mathrm{Pt}$ composite films, respectively. The high CSC value shows that the $\mathrm{IrO}_{x} / \mathrm{Pt}$ composite films may have high charge-injection capacity and have a potential to stimulate cells at a lower voltage. Figure $4 \mathrm{a}$ presents the $\mathrm{CV}$ curves for various composition of $\mathrm{IrO}_{x} / \mathrm{Pt}$ composite films. The $\mathrm{CSC}$ values decreased after the annealing process due to the effect of crystallinity [12,23]. The heat treatment process efficiently crystallized the composite films, and the CSC values changed accordingly. Furthermore, the 200/100 $\mathrm{nm}$ of $\mathrm{IrO}_{x} / \mathrm{Pt}$ composite film presented the largest CSC value of $46.28 \mathrm{mC} / \mathrm{cm}^{2}$ because the sputtered platinum increases the surface roughness of the composite film. Figure $4 \mathrm{~b}$ shows the comparison of the CV curves of as-deposited and annealed $\mathrm{IrO}_{x}$ film $(300 / 0 \mathrm{~nm})$ as well as annealed $\mathrm{Pt}(0 / 100 \mathrm{~nm})$, and the CSC values were $35.22,24.19$, and $1.07 \mathrm{mC} / \mathrm{cm}^{2}$, respectively. $\mathrm{IrO}_{x}$ can largely increase the CSC value compared to the traditional commercial electrode material of $\mathrm{Pt}$. Therefore, we can expect $\mathrm{IrO}_{x}$ to become the next generation biocompatible electrode for implantable neurostimulation devices $[24,25]$.
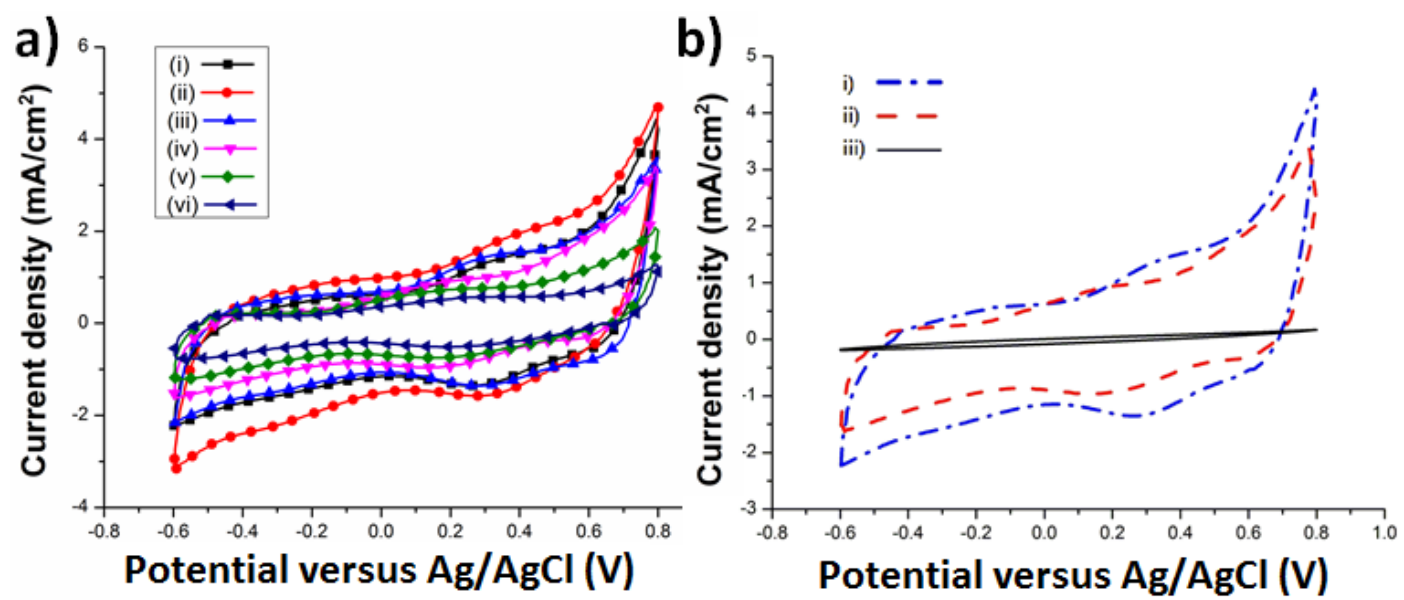

Figure 4. Cyclic voltammograms of (a) as-deposited $\mathrm{IrO}_{x} / \mathrm{Pt}$ composite films with $\mathrm{IrO}_{x} / \mathrm{Pt}$ ratio of (i) 300/0, (ii) 200/100, (iii) 100/200; and annealed $\mathrm{IrO}_{x} / \mathrm{Pt}$ composite films with $\mathrm{IrO}_{x} / \mathrm{Pt}$ ratio of (iv) 300/0, (v) 200/100, (vi) 100/200; (b) charge storage capacity (CSC) comparison of (i) as-deposited $\operatorname{IrO}_{x}$ film, (ii) annealed $\mathrm{IrO}_{x}$ film, and (iii) Pt film.

We further employed the chemical bath deposition of iridium oxide on a bullet-shaped titanium microelectrode $(0.5 \mathrm{~mm}$ in diameter). Noda et al. reported that they developed a retinal prosthesis using the curved titanium microelectrodes [4]. Figure 5a displays the optical microscopy (OM) image of the bullet-shaped titanium microelectrode. $\mathrm{IrO}_{x}$ film was deposited on the surface of the bullet-shaped titanium microelectrode by chemical bath deposition developed in this study. As shown in Figure 5a, the surface of the bullet-shaped titanium microelectrode was uniformly covered by a thin layer of $\mathrm{IrO}_{x}$ film. Figure $5 \mathrm{~b}$ displays the $\mathrm{CV}$ curve of the fifth cycle of the $\mathrm{IrO}_{x}$-coated bullet-shaped titanium microelectrode at $50 \mathrm{mV} \cdot \mathrm{s}^{-1}$. The oxidation/reduction peaks that appeared in the CSC profile of the $\mathrm{IrO}_{x}$-coated bullet-shaped titanium microelectrode were identical to the CSC profiles of the $\mathrm{IrO}_{x}$-coated titanium and $\mathrm{IrO}_{x} / \mathrm{Pt}$-coated titanium shown in Figure 4. Consequently, we successfully implemented chemical bath deposition to replace deposition techniques such as sputtering. In addition, the CSC value of the $\mathrm{IrO}_{x}$-coated bullet-shaped titanium microelectrode was $30.12 \mathrm{mC} / \mathrm{cm}^{2}$ correlated to the electrode performance of the $\mathrm{IrO}_{x}$ thin film using chemical bath deposition. We would like to further explain the reason we only deposited $\mathrm{IrO}_{x}$ on the bullet-shaped titanium microelectrode. The $\mathrm{IrO}_{x}$ and $\mathrm{Pt}$ in the composite films were prepared using chemical bath deposition and DC sputtering, respectively. We only demonstrated the feasibility of the chemical bath deposition of $\operatorname{IrO}_{x}$ on the bullet-shaped titanium microelectrode to prevent cracks on the sputtered $\mathrm{Pt}$ film formed on the curved titanium substrate. However, $\mathrm{IrO}_{x} / \mathrm{Pt}$ composite film can be deposited on the bullet-shaped titanium microelectrode as long as both $\mathrm{IrO}_{x}$ and $\mathrm{Pt}$ films can be prepared using chemical bath deposition [26]. 

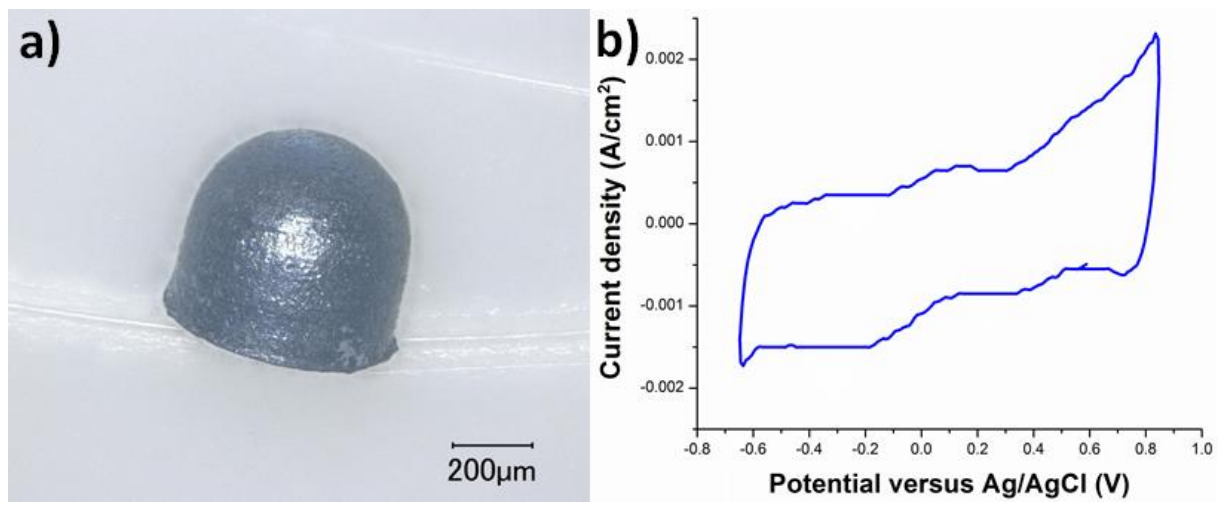

Figure 5. (a) Optical microscope image of $\mathrm{IrO}_{x}$-coated bullet-shaped titanium microelectrode; (b) cyclic voltammogram of $\mathrm{IrO}_{x}$-coated bullet-shaped titanium microelectrode.

In order to evaluate the biocompatibility of the $\mathrm{IrO}_{x} / \mathrm{Pt}$ composite films, an MDA-MB-231 cell line was cultured on top of the $\mathrm{IrO}_{x} / \mathrm{Pt}$ composite films and on a culture dish as the control group. The cell viability was assessed by measuring the optical density (OD) of the resulting solution at $595 \mathrm{~nm}$. The cell viability percentages were calculated as: $\mathrm{OD}_{\text {sample }} / \mathrm{OD}_{\text {control }}$. Figure 6 shows the cell viability results. Each sample of $\mathrm{IrO}_{x} / \mathrm{Pt}$ composite film had a viability of $\sim 90 \%$, which indicates that the $\mathrm{IrO}_{x} / \mathrm{Pt}$ composite film provides a biocompatible environment for cell survival. The $\mathrm{IrO}_{x} / \mathrm{Pt}$ composite films fabricated in this study have good crystallinity and hydrophilicity; these properties can provide a desirable matrix for cell attachment according to studies on the relationship between crystallinity and biocompatibility $[10,27]$.

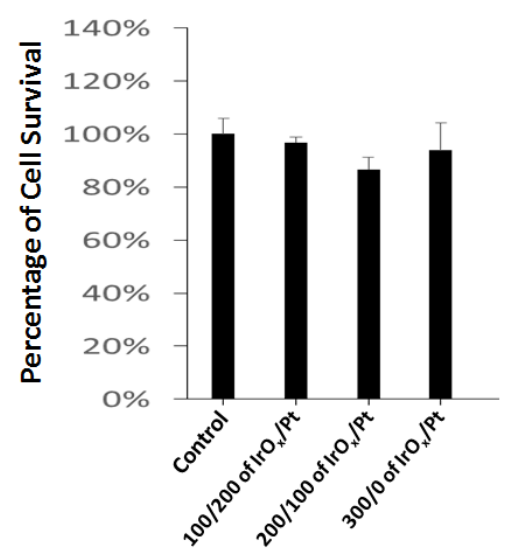

Figure 6. Cell viability percentage of $\mathrm{IrO}_{x} / \mathrm{Pt}$ composite films.

\section{Conclusions}

In this study, we successfully developed a hybrid deposition process to prepare $\mathrm{IrO}_{x} / \mathrm{Pt}$ composite films on titanium substrates by combining chemical bath deposition and sputtering. A relationship is found as well; when the deposited thickness of $\mathrm{IrO}_{x}$ increases, the surface roughness also increases, but the contact angle decreases. These $\mathrm{IrO}_{x} / \mathrm{Pt}$ composite films with different compositions can be used for many applications. Furthermore, the chemical bath deposition is a simple and inexpensive alternative for fabrication. In addition, the $\mathrm{IrO}_{x} / \mathrm{Pt}$ composite films were characterized by their morphology, composition, crystallinity, surface roughness by SEM, XRD, and contact angle, respectively. As a result, the $\mathrm{IrO}_{x} / \mathrm{Pt}$ composite films present higher charge storage capacities than $\mathrm{Pt}$ film does, so they can be utilized in implantable neurostimulation devices and largely enhance the efficiency. Additionally, we successfully demonstrated the chemical bath deposition of $\operatorname{IrO}_{x}$ film on the surface of the bullet-shaped titanium microelectrode and the redox behavior of the $\operatorname{IrO}_{x}$-coated bullet-shaped titanium microelectrode was identical to that of the $\mathrm{IrO}_{x}$-coated titanium sheet. 
Author Contributions: Conceptualization, P.-C.C. and J.O.; Methodology, P.-C.C.; Software, T.-W.C. and C.-N.H.; Validation, P.-C.C., T.N., T.T., and J.O.; Formal Analysis, P.-C.C., T.N., and T.-W.C.; Investigation, P.-C.C., T.N., T.T., and J.O.; Resources, P.-C.C. and J.O.; Data Curation, P.-C.C., T.N., T.T., and J.O.; Writing-Original Draft Preparation, P.-C.C.; Writing-Review \& Editing, P.-C.C. and J.O.; Supervision, P.-C.C. and J.O.; Project Administration, P.-C.C. and J.O.; Funding Acquisition, P.-C.C. and J.O.

Funding: This research was funded by financial supports from the Ministry of Science and Technology of Taiwan (MOST 106-2221-E-027-048, 107-2221-E-027-009-MY2, and 107-2633-B-009-003) and the Japan Science and Technology Agency (JST) under funding program of The Japanese-Taiwanese Cooperative Program on "Bioelectronics" and "Biophotonics".

Acknowledgments: The authors acknowledge Precision Research and Analysis Center at NTUT and partly by the Center for Neuromodulation Medical Electronics Systems from The Featured Areas Research Center Program within the framework of the Higher Education Sprout Project by the Ministry of Education in Taiwan.

Conflicts of Interest: The authors declare no conflict of interest.

\section{References}

1. Cogan, S.F. Neural stimulation and recording electrodes. Annu. Rev. Biomed. Eng. 2008, 10, $275-309$. [CrossRef] [PubMed]

2. Liu, X.; Chu, P.K.; Ding, C. Surface modification of titanium, titanium alloys, and related materials for biomedical applications. Mater. Sci. Eng. R 2004, 47, 49-121. [CrossRef]

3. Rack, H.J.; Qazi, J.I. Titanium alloys for biomedical applications. Mater. Sci. Eng. C 2006, 26, $1269-1277$. [CrossRef]

4. Noda, T.; Sasagawa, K.; Tokuda, T.; Terasawa, Y.; Tashiro, H.; Kanda, H.; Fujikado, T.; Ohta, J. Performance improvement and functionalization of an electrode array for retinal prosthesis by iridium oxide coating and introduction of smart-wiring technology using cmos microchips. Sens. Actuators A 2014, 211, 27-37. [CrossRef]

5. Merrill, D.R.; Bikson, M.; Jefferys, J.G. Electrical stimulation of excitable tissue: Design of efficacious and safe protocols. J. Neurosci. Methods 2005, 141, 171-198. [CrossRef] [PubMed]

6. Pine, J. Recording action potentials from cultured neurons with extracellular microcircuit electrodes. J. Neurosci. Methods 1980, 2, 19-31. [CrossRef]

7. Pan, Y.L.; Noda, T.; Sasagawa, K.; Tokuda, T.; Ohta, J. Sputtering condition optimization of sputtered irox and tin stimulus electrodes for retinal prosthesis. IEEJ Trans. Electr. Electron. Eng. 2013, 8, 310-312. [CrossRef]

8. Weiland, J.D.; Anderson, D.J.; Humayun, M.S. In vitro electrical properties for iridium oxide versus titanium nitride stimulating electrodes. IEEE Trans. Biomed. Eng. 2002, 49, 1574-1579. [CrossRef] [PubMed]

9. Meyer, R.D.; Cogan, S.F.; Nguyen, T.H.; Rauh, R.D. Electrodeposited iridium oxide for neural stimulation and recording electrodes. IEEE Trans. Neural Syst. Rehabil. Eng. 2001, 9, 2-11. [CrossRef] [PubMed]

10. Thanawala, S.; Palyvoda, O.; Georgiev, D.G.; Khan, S.P.; Al-Homoudi, I.A.; Newaz, G.; Auner, G. A neural cell culture study on thin film electrode materials. J. Mater. Sci. Mater. Med. 2007, 18, 1745-1752. [CrossRef] [PubMed]

11. Hackwood, S.; Dayem, A.H.; Beni, G. Amorphous-nonmetal-to-crystalline-metal transition in electrochromic iridium oxide films. Phys. Rev. B 1982, 26, 471. [CrossRef]

12. Wessling, B.; Besmehn, A.; Mokwa, W.; Schnakenberg, U. Reactively sputtered iridium oxide influence of plasma excitation and substrate temperature on morphology, composition, and electrochemical characteristics. J. Electrochem. Soc. 2007, 154, F83-F89. [CrossRef]

13. Slavcheva, E.; Vitushinsky, R.; Mokwa, W.; Schnakenberg, U. Sputtered iridium oxide films as charge injection material for functional electrostimulation. J. Electrochem. Soc. 2004, 151, E226-E237. [CrossRef]

14. Yamanaka, K. Anodically electrodeposited iridium oxide films (AEIROF) from alkaline solutions for electrochromic display devices. Jpn. J. Appl. Phys. 1989, 28, 632-637. [CrossRef]

15. Robblee, L.S.; Mangaudis, M.J.; Lasinsky, E.D.; Kimball, A.G.; Brummer, S.B. Charge injection properties of thermally-prepared iridium oxide films. MRS Online Proc. Lib. Arch. 1985, 55, 303. [CrossRef]

16. Chen, J.Y.; Chen, Y.M.; Sun, Y.; Lee, J.F.; Chen, S.Y.; Chen, P.C.; Wu, P.W. Chemical bath deposition of IrO2 films on ITO substrate. Ceram. Int. 2014, 40, 14983-14990. [CrossRef] 
17. Chen, Y.M.; Chung, T.W.; Wu, P.W.; Chen, P.C. A cost-effective fabrication of iridium oxide films as biocompatible electrostimulation electrodes for neural interface applications. J. Alloy. Compd. 2017, 692, 339-345. [CrossRef]

18. Negi, S.; Bhandari, R.; Rieth, L.; Van Wagenen, R.; Solzbacher, F. Neural electrode degradation from continuous electrical stimulation: Comparison of sputtered and activated iridium oxide. J. Neurosci. Methods 2010, 186, 8-17. [CrossRef] [PubMed]

19. Niinomi, M.; Nakai, M.; Hieda, J. Development of new metallic alloys for biomedical applications. Acta Biomater. 2012, 8, 3888-3903. [CrossRef] [PubMed]

20. Chung, R.J.; Ou, K.L.; Tseng, W.K.; Liu, H.L. Controlled release of BMP-2 by chitosan/ $\gamma$-PGA polyelectrolyte multilayers coating on titanium alloy promotes osteogenic differentiation in rat bone-marrow mesenchymal stem cells. Surf. Coat. Technol. 2016, 303, 283-288. [CrossRef]

21. Bloyce, A.; Qi, P.Y.; Dong, H.; Bell, T. Surface modification of titanium alloys for combined improvements in corrosion and wear resistance. Surf. Coat. Technol. 1998, 107, 125-132. [CrossRef]

22. Miyashita, K.; Kuroda, S.; Ubukata, T.; Ozawa, T.; Kubota, H. Enhanced effect of vacuum-deposited $\mathrm{SiO}_{2}$ overlayer on photo-induced hydrophilicity of $\mathrm{TiO}_{2}$ film. J. Mater. Sci. 2001, 36, 3877-3884. [CrossRef]

23. Negi, S.; Bhandari, R.; Rieth, L.; Solzbacher, F. In vitro comparison of sputtered iridium oxide and platinum-coated neural implantable microelectrode arrays. Biomed. Mater. 2010, 5, 015007. [CrossRef] [PubMed]

24. Boehler, C.; Oberueber, F.; Schlabach, S.; Stieglitz, T.; Asplund, M. Long-term stable adhesion for conducting polymers in biomedical applications: $\mathrm{IrO}_{x}$ and nanostructured platinum solve the chronic challenge. ACS Appl. Mater. Interfaces 2016, 9, 189-197. [CrossRef] [PubMed]

25. Zeng, Q.; Xia, K.; Sun, B.; Yin, Y.; Wu, T.; Humayun, M.S. Electrodeposited iridium oxide on platinum nanocones for improving neural stimulation microelectrodes. Electrochim. Acta 2017, 237, 152-159. [CrossRef]

26. Wu, Y.J.; Chung, T.W.; Huang, J.Q.; Wu, P.W.; Chen, P.C.; Lee, J.F.; Chan, T.S. Conformal deposition of Pt on titania nanotubes to produce a bio-electrode for neuro-stimulating applications. Electrochem. Commun. 2018, 88, 61-66. [CrossRef]

27. Göbbels, K.; Kuenzel, T.; van Ooyen, A.; Baumgartner, W.; Schnakenberg, U.; Bräunig, P. Neuronal cell growth on iridium oxide. Biomaterials 2010, 31, 1055-1067. [CrossRef] [PubMed] 